\title{
Automated data monitoring of MEMS cleanroom parametric requirements
}

\author{
Jean M. Capanang ${ }^{1}$, Jobelle P. Panganiban ${ }^{2}$, Glenn N. Ortiz ${ }^{3}$, Mark Joseph B. Enojas ${ }^{4}$ \\ ${ }^{1,2}$ Analog Devices Inc., General Trias Cavite, Philippines \\ ${ }^{3}$ Industry-based Program, Technological University of the Philippines Taguig, Philippines \\ ${ }^{4}$ Bachelor of Engineering and Allied Department, Technological University of the Philippines Taguig, Philippines
}

\begin{tabular}{l} 
Article Info \\
\hline Article history: \\
Received Jan 13, 2021 \\
Revised Jul 7, 2021 \\
Accepted Jul 9, 2021 \\
\hline
\end{tabular}

\section{Keywords:}

Automated data monitoring

system

Cleanroom

Humidity

Microelectromechanical

systems

Particle count

Temperature

\begin{abstract}
Cleanroom parameters such as temperature, relative humidity, and particle count are vital in maintaining cleanliness. People and machines working inside the cleanroom are main contributors for the sudden changes of these parameters. Measurements and monitoring of these parameters are therefore necessary to reduce rejects and downtime in the production of micro-electromechanical systems (MEMS). This paper presents a method of development of an automated data monitoring of MEMS cleanroom parametric requirements. The prototype developed uses DHT11 sensor and Sharp dust sensor for measuring the temperature, humidity, and particle count respectively which are displayed in an LCD display. These parameters are recorded through a data logger for analysis and control. Additionally, a graphical user interface was also developed using visual studio for the working personnel and for supervisory monitoring and control. As a result, the possible quality compromise in the production of MEMS is detected when the monitored parameters are beyond the range.
\end{abstract}

This is an open access article under the $\underline{C C B Y-S A}$ license.

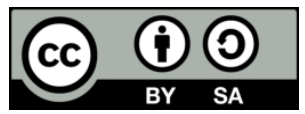

\section{Corresponding Author:}

Jean M. Capanang

Analog Devices Inc. General Trias Cavite, Philippines

Technological University of the Philippines Taguig, Philippines

Km, 14 East Service Rd. Western Bicutan, Taguig City, Philippines

Email: Jean.Capanang@analog.com

\section{INTRODUCTION}

The ISO 14644-1 provides the standard cleanroom control reference as the basis for classifying the cleanroom within the production floor of electronic products companies. Cleanrooms in electronic companies vary according to each focus area and handled products. The micro-electromechanical systems (MEMS) cleanroom for wafer level chip scale package (WLCSP) is an enclosed work area employing controls where the concentration of airborne particles with temperature, humidity, non-static pressure, and airflow controls are required. This area holds the processing of wafer related products. It is the responsibility of the production floor management to produce good products from the procedures of testing wafers and down to packaging each die.

The presence of contaminants is vital in the production of very sensitive to dirt electronic packages [1]. The products should be of acceptable quality. The presence of micro dust and the sudden changes in temperature, are among those circumstances where there are high chances of product quality compromise. MEMS cleanroom is one of those rooms that is the strictest with regards to cleanroom parameters [2]-[4]. Temperature, humidity, and foreign particles have great influence in the microfabrication of MEMS [5]-[9]. It is critical that even before fabrication, simulations should be conducted to see that other 
parameters can vitally affect the fabrication process and the performance of MEMS products [10]-[13]. It undergoes micromachining that even small changes in the room temperature might have an effect in the structure. Some of the effects on the changes in these parameters may lead to creation of particulates, jamming of moving parts, deformation of the components, and even stiction [14]-[17]. Since most of the MEMS developed are for sensing, critical parameters have to be monitored and controlled [18]-[20].

Before laying an automation scheme in the cleanroom process, one must first take a closer look at its condition and the availability of sensors and other resources needed. In an investigative study on a cleanroom in one of the microelectronic manufacturers in the Philippines, it has been found out that on-site sensors for temperature and relative humidity across the plant are available but the real-time reading is not visible to the personnel inside the cleanroom. Authorized personnel do the manual data gathering every two weeks to monitor the airborne particles. Any fluctuation with this parameter is not noticeable for the people working inside. Therefore, automated monitoring is needed so that the quality of the products will not be compromised, and thereby avoiding rejects and downtime.

Many processes in the production of electronic packages have been automated such as the pre-seal bake process, which in turn affects the temperature in the production line room [21]. Monitoring of parameters is of high importance in critical environments. Some examples of these monitoring systems use different computing software and controllers [22], [23]. Others have also presented wireless communication for monitoring mobility for supervisory control [24]-[29]. Different controls like proportional-integralderivative (PID) and fuzzy systems are used for controlling these parameters because of the complexity and nonlinearity [30]-[32]. In critical processes such as in MEMS, careful monitoring of the temperature, humidity, and sanity or cleanliness of the room by particle count is vital [33], [34].

This research presents a method of development of an automated data monitoring of MEMS' cleanroom parametric requirements. A temperature measurement system was built which uses a DHT 11 sensor kit, which is common and best suited for measuring temperature and humidity in a clean room. A Sharp dust sensor is used for the particle count. It provides visibility of the parameters through a developed graphical user interface (GUI) monitor. Additionally, audible and visual alerts that display the temperature, relative humidity, and particle count inside the room are included. When the real-time parameters exceed the allowable range, an alarm will be triggered. The prototype will be helpful in determining the frequency of cleaning the cleanroom.

\section{METHOD}

\subsection{Project design and development}

This project monitors the quality of the environment in the MEMS cleanroom area for the parameters: temperature, humidity and particle count. Airborne particles, which are potential contaminants should be controlled in specified limits. The project will be well situated inside the cleanroom where the parameters mentioned will be visible to the personnel working inside. In a nutshell, the project is presented in Figure 1.

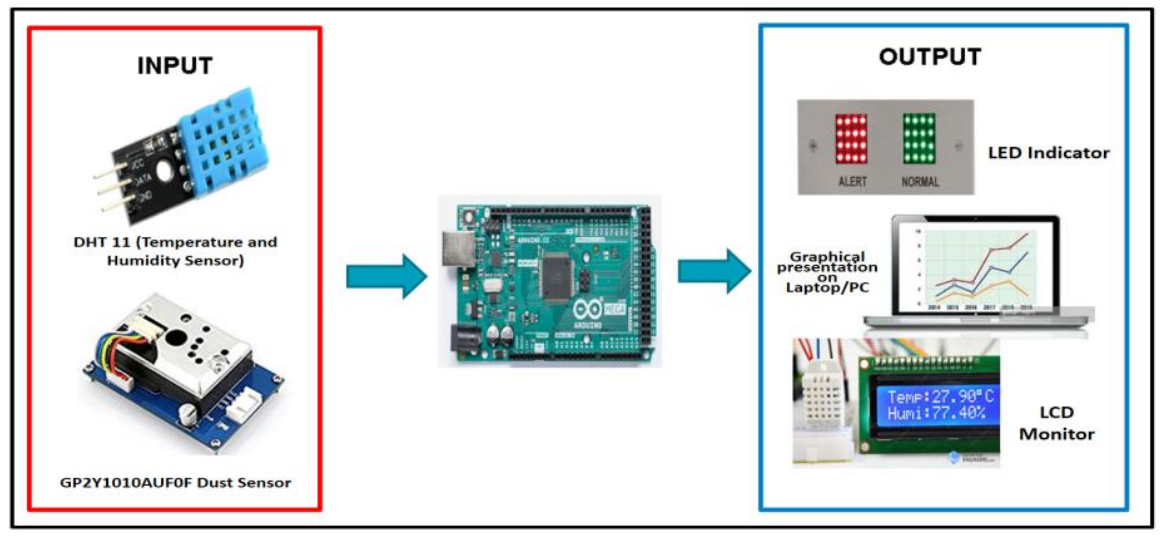

Figure 1. Project block diagram

Temperature and humidity is measured using the DHT 11 sensor. It can be configured directly to a microcontroller for analysis and control. Dust particles are detected and measured using the GP2Y1010AU0F 
dust sensor. The data collected are sent to an Arduino ATMEGA 2560 microcontroller. It is also displayed on the LCD monitor. The sampling period set is one minute, or as preferred by the personnel using the prototype. See Figure 2. An audible alarm and LED light will be triggered when the sensed data is out of range or tolerance to one of the parameters. All the data collected is stored in a data logger in .csv format so that it can be graphically presented. The interconnection of the devices is presented in Figure 3 . The schematic diagram for interconnecting these devices is shown in Figure 4.
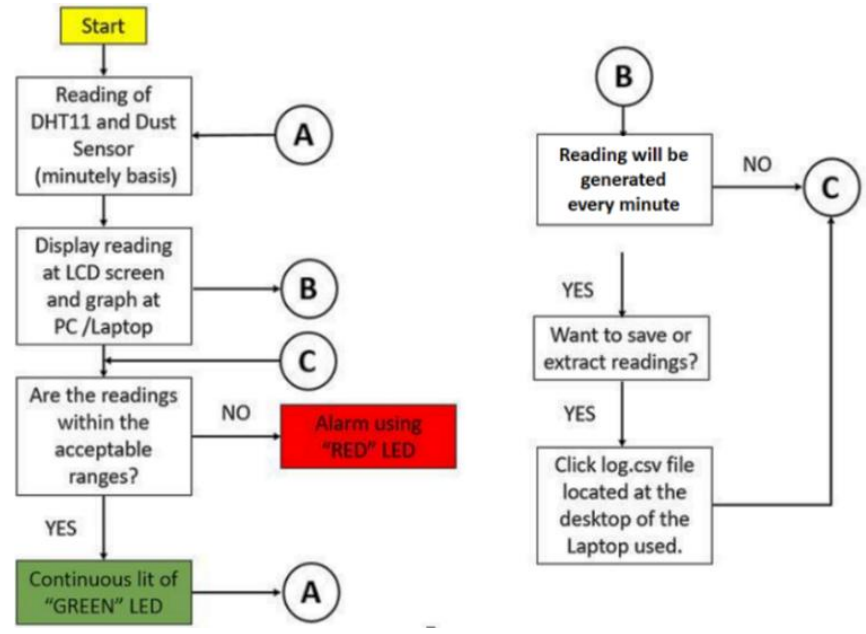

Figure 2. System flow chart

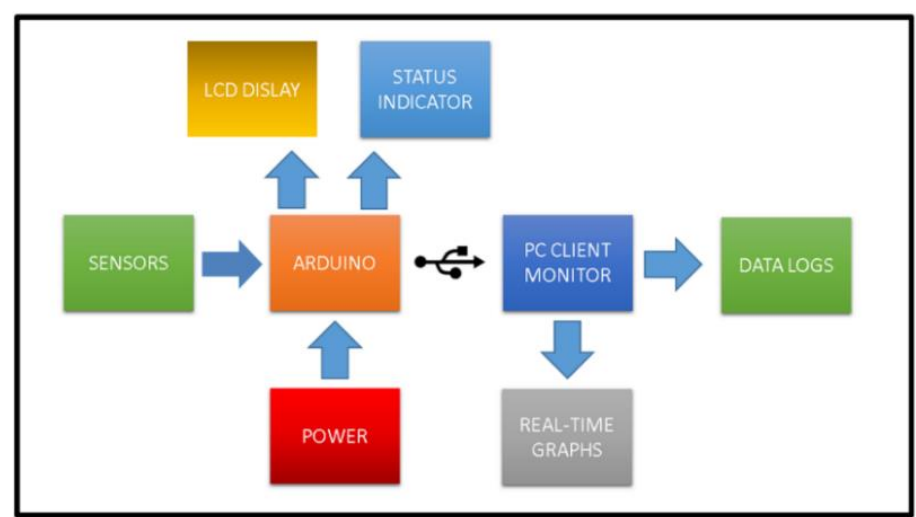

Figure 3. Interfacing block diagram

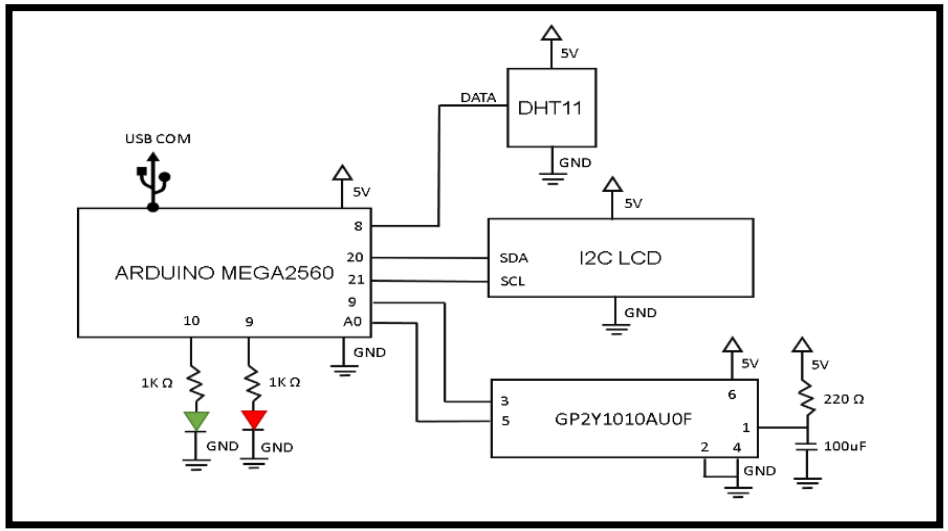

Figure 4. Control system schematic diagram 


\subsection{Data processing}

A serial connection is established in processing the data collected from the sensors down to the controller. See Figure 4 for the schematic diagram. An executable application was developed to run the system automatically when the computer is booted. A LAN connection was also established for supervisory monitoring and data logging. The temperature readings are displayed in degrees Celsius, relative humidity in $\% \mathrm{RH}$, and particles count in particles per cubic meter (PCM). Each parameter is individually presented in graphs with respect to its time stamp.

\subsection{Tests and evaluation}

A comparative analysis is conducted between the data collected in a cleanroom and non-cleanroom. This analysis is conducted so that a real scenario of detecting different parameter conditions can be tested and evaluated. The dust sensor is calibrated with the equivalent function according to the sensor characteristics. See Figure 5. This sensor is selected based on the working parameter in the cleanroom with margins that can detect large deviations from the working parameters for the purpose of evaluating the differences in the reading between the cleanroom and non-cleanroom.

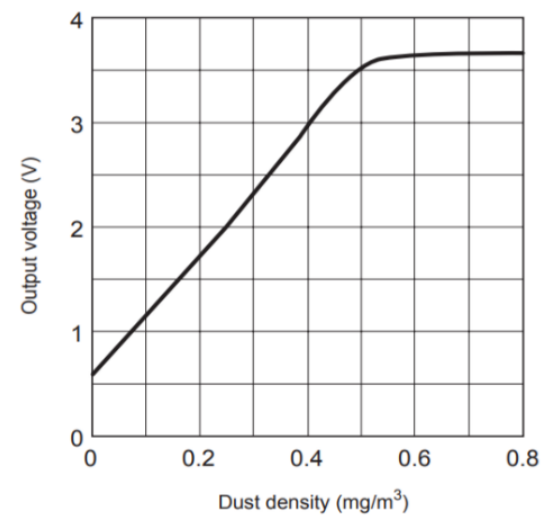

Figure 5. Dust density vs. output voltage of the dust sensor (Sharp GP2Y1010AUF0F)

\section{RESULTS AND DISCUSSION}

\subsection{Project development}

The assembly consists of a circuit board and terminals in which the elements of the prototype will be connected. The prototype is protected by an enclosure as presented in Figure 6(a) and Figure 6(b). The temperature and dust sensors are connected serially to the microcontroller unit for monitoring and control. See Figure 6(c) and Figure 6(d) for the monitoring of the temperature and humidity parameters.

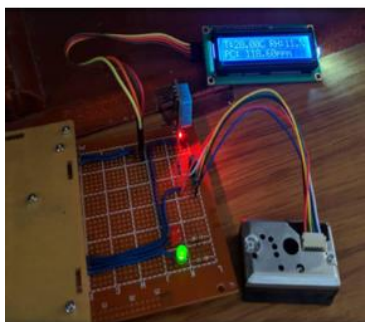

(a)

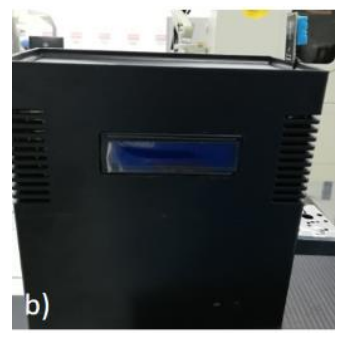

(b)

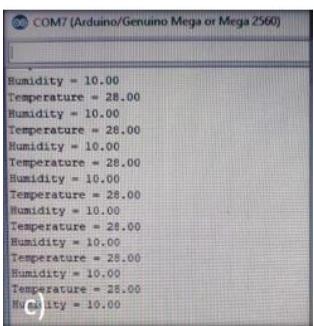

(c)

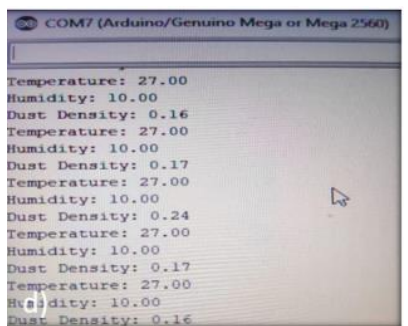

(d)

Figure 6. Prototype; (a) test setup, (b) prototype enclosure, (c) DHT11 sensor monitor, (d) dust sensor monitor

\subsection{Software design and virtual representation}

The visual representation of the data processed by the controller is presented in graphs by a visual C\# program for the computer GUI as presented in Figure 7. For the quick monitoring of the parameters an LCD display is added for the personnel checking the device. This is presented in Figure 8 . This visual monitor can be helpful when attenuators malfunction. 


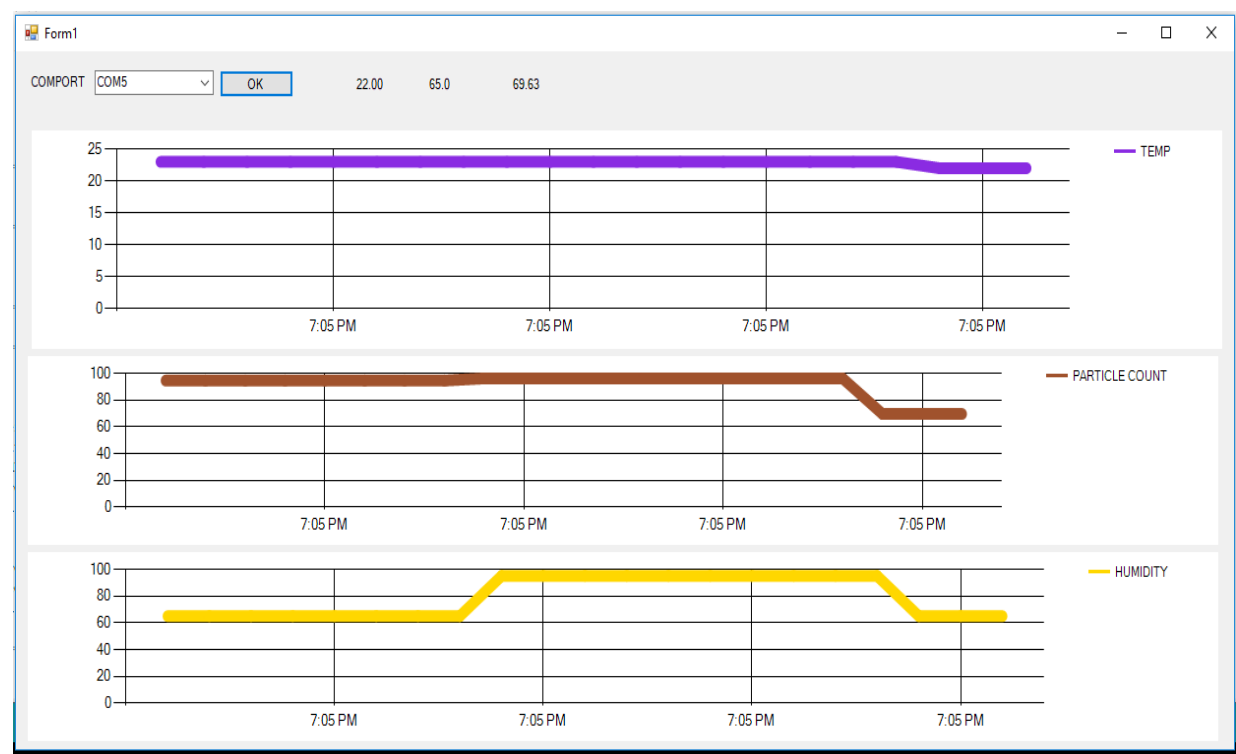

Figure 7. Graphical presentation of parameters in the GUI

Figure 8. LCD display for monitoring

\subsection{Field Tests and Evaluation}

The prototype is tested in both cleanroom and non-clean rooms. The sensors are situated in the production area close to the personnel and the product being operated. Figure 9 presents the temperature samples monitored for each minute for 20 minutes. The controlled working temperature inside the cleanroom is at $21-23^{\circ} \mathrm{C}$ while in the non-cleanroom is at $25-27^{\circ} \mathrm{C}$. The prototype displays an alarm when it is placed in the non-cleanroom because of the increase in temperature. Meanwhile, the relative humidity in the cleanroom is at $64-67 \%$ RH. See Figure 10 the particle count on the other hand is not greater than 120 particles for the cleanroom. The particle count in the non-cleanroom is at 638-650 PPM for the 20-minute sampling. These are illustrated in Figure 11 respectively.

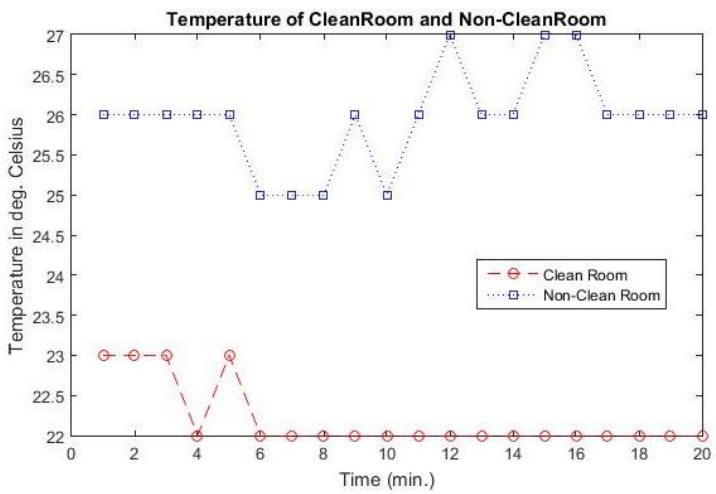

Figure 9. Temperature in cleanroom and noncleanroom

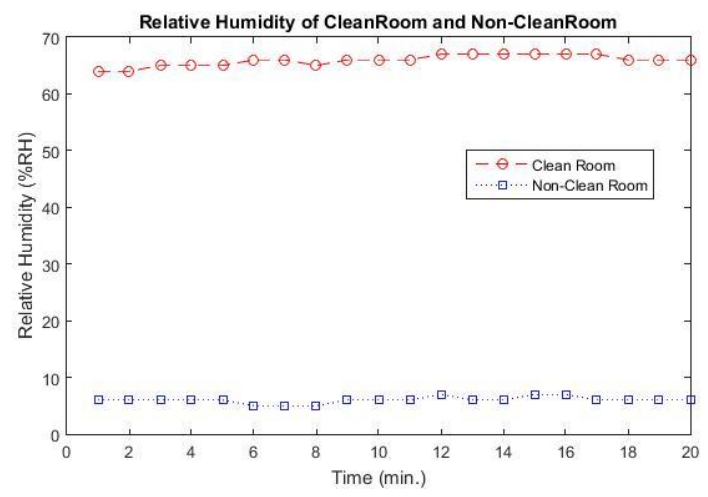

Figure 10. Relative humidity in cleanroom and noncleanroom 


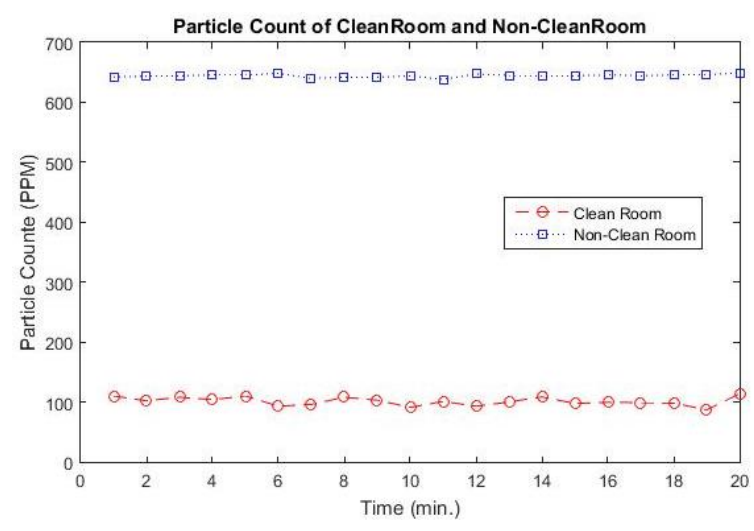

Figure 11. Particle count in cleanroom and non-cleanroom

The differences in the data gathered for each parameter for both cleanroom and non-cleanroom are significant evidence that the prototype works well in monitoring these parameters. The alarms can be adjusted based on the collected working levels for each parameter. Deviation from the specified ranges of parametric requirements will trigger the alarm to call out the attention for cleanup or maintenance.

\section{CONCLUSION AND FUTURE WORK}

The production of MEMS needs strict monitoring of environmental parameters in order to avoid compromising the product quality. This project enabled automating the monitoring system of the MEMS cleanroom so that unscheduled cleaning might be conducted as needed. The data are displayed in both GUI and LCD display for monitoring for both field personnel and supervisory personnel. The significant changes in the readings of the three parameters, particularly; temperature, relative humidity, and particle count (between an average of $22.2{ }^{\circ} \mathrm{C}$ and $25.95{ }^{\circ} \mathrm{C}, 65.9 \% \mathrm{RH}$ and 6\% RH, and 101.125 PPM and 644.2775 PPM respectively) collected in a 20-minute data gathering, validating the effectiveness of the prototype. The data logs are also helpful in investigating scenarios on how to avoid MEMS' compromised production quality.

In the future, multiple sensors will be placed across the cleanroom for monitoring and supervisory control. Wireless connectivity can also be integrated for mobile applications. This opens a window for improvement for MEMS cleanroom control and maintenance.

\section{ACKNOWLEDGEMENTS}

First of all, the authors acknowledge the Lord Jesus Christ as the source of all provision. The authors also acknowledge Analog Devices Inc. General Trias Cavite, Philippines and the Technological University of the Philippines Taguig for the fruitful collaboration in conducting this study for industrial automation.

\section{REFERENCES}

[1] C. R. Copeland, C. D. Mcgray, J. Geist, and S. M. Stavis, "Particle Tracking of Microelectromechanical System Performance and Reliability," in Journal of Microelectromechanical Systems, vol. 27, no. 6, pp. 948-950, Dec. 2018, doi: 10.1109/JMEMS.2018.2874771.

[2] M. Hirano, H. Kuwano, and J. W. Weijtmans, "Superlubricity Mechanism for Micro Electromechanical Systems," in Proceedings IEEE The Tenth Annual International Workshop on Micro Electro Mechanical Systems. An Investigation of Micro Structures, Sensors, Actuators, Machines and Robots, 1997, pp. 436-441, doi: 10.1109/MEMSYS.1997.581885.

[3] A. Izadbakhsh and S. M. R. Rafiei, "Robust Control Methodologies for Optical Micro Electro Mechanical System New approaches and Comparison," in 2008 13th International Power Electronics and Motion Control Conference, 2008, pp. 2102-2107, doi: 10.1109/EPEPEMC.2008.4635577.

[4] O. Tabata, K. Shomaoka, and S. Siguyama, "In Situ Observation and Analysis of Wet Etching Process for Micro Electro Mechanical Systems," in [1991] Proceedings. IEEE Micro Electro Mechanical Systems, 1991, pp. 99-102, doi: 10.1109/MEMSYS.1991.114776.

[5] S. Grauby, S. Dilhaire, S. Jorez, and W. Claeys, "Temperature Variation Mapping of a Microelectromechanical System by Thermoreflectance Imaging," in IEEE Electron Device Letters, vol. 26, no. 2, pp. 78-80, Feb. 2005, doi: 10.1109/LED.2004.841468. 
[6] Z. Peng et al., "Impact of Humidity on Dielectric Charging in RF MEMS Capacitive Switches," in IEEE Microwave and Wireless Components Letters, vol. 19, no. 5, pp. 299-301, May 2009, doi: 10.1109/LMWC.2009.2017595.

[7] M. Hon, F. W. DelRio, C. Carraro, and R. Maboudian, "Effects of Relative Humidity and Actuation Voltage on MEMS," in TRANSDUCERS 2007 - 2007 International Solid-State Sensors, Actuators and Microsystems Conference, 2007, pp. 367-370, doi: 10.1109/SENSOR.2007.4300144.

[8] T. Suga and N. Hosoda, "A Novel Approach to Assembly and Interconnection for Micro Electro Mechanical Systems," in Proceedings IEEE Micro Electro Mechanical Systems. 1995, 1995, pp. 413-418, doi: 10.1109/MEMSYS.1995.472589.

[9] L. Zhan, H. San, G. Li, P. Xu, and X. Chen, "Effects of Si-nanocrystal formation in dielectric layers on reliability of RF MEMS Switches," in 2008 3rd IEEE International Conference on Nano/Micro Engineered and Molecular Systems, 2008, pp. 548-551, doi: 10.1109/NEMS.2008.4484392.

[10] L. G. Salmon, "Testing Requirements for Microelectromechanical Systems (MEMS)," in 1998 IEEE AUTOTESTCON Proceedings. IEEE Systems Readiness Technology Conference. Test Technology for the 21st Century (Cat. No.98CH36179), 1998, pp. 160-, doi: 10.1109/AUTEST.1998.713436.

[11] X. Zhang, X. Ke, and Z. Zhang, "Research on Micro-Electro-Mechanical-Systems digital geophone," in 2010 International Conference on Artificial Intelligence and Computational Intelligence, 2010, pp. 414-417, doi: 10.1109/AICI.2010.324..

[12] X. Zhao, B. Lu, G. Lu, and Y. Huang, "Virtual Reality-Based Rapid Prototyping Design for Micro-ElectroMechanical System," in 1997 IEEE International Conference on Intelligent Processing Systems (Cat. No.97TH8335), 1997, pp. 1765-1768 vol.2, doi: 10.1109/ICIPS.1997.669358.

[13] S. Saadon and O. Sidek, "Transient analysis of ambient vibration-based micro-electro-mechanical systems (MEMS) piezoelectric energy harvester using ANSYS and COVENTORWARE approaches," in 2011 IEEE International Conference on Computer Applications and Industrial Electronics (ICCAIE), 2011, pp. 41-44, doi: 10.1109/ICCAIE.2011.6162101.

[14] F. Sammoura, M. Hancer, and K. Yang, "The Effect of Surface Chemistry on MEMS Stiction in an UltralowHumidity Environment," in Journal of Microelectromechanical Systems, vol. 20, no. 2, pp. 522-526, April 2011, doi: 10.1109/JMEMS.2010.2100029.

[15] F. Sammoura, A. Sparks, W. Sawyer, M. Bhagavat, M. Judy, and K. Yang, "Stiction in Low Humidity Environment," in 2009 IEEE 22nd International Conference on Micro Electro Mechanical Systems, 2009, pp. 88-91, doi: 10.1109/MEMSYS.2009.4805326.

[16] R. Ranganathan, G. Sivakumar, R. Gale, and T. Dallas, "Characterization of Stiction Accrual in a MEMS," in Journal of Microelectromechanical Systems, vol. 18, no. 5, pp. 1149-1159, Oct. 2009, doi: 10.1109/JMEMS.2009.2027503.

[17] P. Mccluskey, "Design for Reliability of Micro-Electro-Mechanical Systems (MEMS)," in 52nd Electronic Components and Technology Conference 2002. (Cat. No.02CH37345), 2002, pp. 760-762, doi: 10.1109/ECTC.2002.1008183.

[18] S. Scott, F. Sadeghi, and D. Peroulis, "An Inherently-Robust $300{ }^{\circ} \mathrm{C}$ MEMS Temperature Sensor for Wireless Health Monitoring of Ball and Rolling Element Bearings," in SENSORS, 2009 IEEE, 2009, pp. 975-978, doi: 10.1109/ICSENS.2009.5398204.

[19] H. Ooe, T. Eimori, M. Nomura, H. Nishikawa, K. Fujimoto, and T. Hasegawa, "Low Drift MEMS Humidity Sensor by Intermittent Heating," in 2015 IEEE International Meeting for Future of Electron Devices, Kansai (IMFEDK), 2015, pp. 118-119, doi: 10.1109/IMFEDK.2015.7158578.

[20] T. Fujita, Y. Fukumoto, F. Suzuki, and K. Maenaka, "SOI-MEMS Sensor for Multi-Environmental SensingSystem," in 2007 Fourth International Conference on Networked Sensing Systems, 2007, pp. 146-149, doi: 10.1109/INSS.2007.4297410.

[21] R. P. Gamboa, G. N. Ortiz, and M. J. B. Enojas "Automated Sequential Controller for Pre-Seal Bake Process of Microelectronic Packages," Int. J. Adv. Trends Comput. Sci. Eng., vol. 9, no. 1.3, pp. 240-246, 2020, doi: 10.30534/ijatcse/2020/3691.32020.

[22] H. Xiang, K. Wang, and Z. Li, "Monitored Control System of Temperature / humidity for Ammunition Storehouse Based on LabVIEW," in 2011 First International Conference on Instrumentation, Measurement, Computer, Communication and Control, 2011, pp. 172-175, doi: 10.1109/IMCCC.2011.52.

[23] G. Shaofeng, M. Jianlin, and W. Xiaodong, "A Temperature and Humidity Monitoring System Based on LabVIEW," in 2013 Fourth International Conference on Digital Manufacturing \& Automation, 2013, pp. 84-87, doi: 10.1109/ICDMA.2013.21.

[24] J. Li, X. Xu, J. Cao, W. Dai, and J. Zhang, "Indoor Environment Intelligent Monitoring System," in 2018 IEEE International Conference on Mechatronics and Automation (ICMA), 2018, pp. 1446-1451, doi: 10.1109/ICMA.2018.8484267.

[25] R. Chachan et al., "Designing of an Intelligent Temperature cum Humidity Monitoring System," in 2015 Annual IEEE India Conference (INDICON), 2015, pp. 1-6, doi: 10.1109/INDICON.2015.7443728.

[26] T. Adiono, M. Y. Fathany, S. Fuada, I. G. Purwanda, and S. F. Anindya, "A Portable Node of Humidity and Temperature Sensor for Indoor Environment Monitoring," in 2018 3rd International Conference on Intelligent Green Building and Smart Grid (IGBSG), 2018, pp. 1-5, doi: 10.1109/IGBSG.2018.8393575.

[27] Y. Zhou, Q. Zhou, Q. Kong, and W. Cai, "Wireless temperature \& humidity monitor and control system," in 2012 2nd International Conference on Consumer Electronics, Communications and Networks (CECNet), 2012, pp. 2246-2250, doi: 10.1109/CECNet.2012.6201725. 
[28] L. Ke, H. T.-lei and L. lifang, "Design of Temperature and Humidity Monitoring System Based on Zigbee Technology," in 2009 Chinese Control and Decision Conference, 2009, pp. 3628-3631, doi: 10.1109/CCDC.2009.5192850.

[29] W. Ge, H. Lai, M. Qi, and L. Cui, "Design of Temperature and Humidity Monitoring Terminal System Based on Android," in 2012 3rd International Conference on System Science, Engineering Design and Manufacturing Informatization, 2012, pp. 98-100, doi: 10.1109/ICSSEM.2012.6340776.

[30] X. Zhang and B. Chang, "Research of Temperature and Humidity Monitoring System Based on WSN and Fuzzy Control V4-301," in Proceedings of 2011 International Conference on Electronics and Optoelectronics, 2011, pp. V4-300-V4-303, doi: 10.1109/ICEOE.2011.6013489.

[31] L. Zheng, Y. Ying, and W. Wang, “Automatic Monitoring System of Temperature-humidity for Lab," in 2010 Chinese Control and Decision Conference, 2010, pp. 4258-4261, doi: 10.1109/CCDC.2010.5498394.

[32] B. Chang and X. Zhang, "Design of indoor temperature and humidity monitoring system based on CC2430 and fuzzy-PID," in Proceedings of 2011 Cross Strait Quad-Regional Radio Science and Wireless Technology Conference, 2011, pp. 980-984, doi: 10.1109/CSQRWC.2011.6037121.

[33] N. Menant, D. Faye, P. Nouet, X. Lafontan and D. Lellouchi, "Monitoring of particle deposition in cleanrooms : state-of-the-art," in 2014 Symposium on Design, Test, Integration and Packaging of MEMS/MOEMS (DTIP), 2014, pp. 1-4, doi: 10.1109/DTIP.2014.7056699.

[34] L. Wang, J. Tang and Q. Huang, "Effect of Environmental Humidity on Dielectric Charging Effect in RF MEMS Capacitive Switches Based on C - V Properties," in Journal of Microelectromechanical Systems, vol. 22, no. 3, pp. 637-645, June 2013, doi: 10.1109/JMEMS.2012.2237384.

\section{BIOGRAPHIES OF AUTHORS}

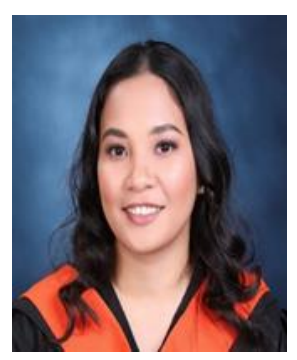

Jean M. Capanang is a graduate of Bachelor of Science in Electronics and Communications Engineering at the Technological University of the Philippines Taguig. Currently, she is working in the engineering division in Analog Devices Inc., General Trias Cavite, Philippines. E-mail: Jean.Capanang@analog.com

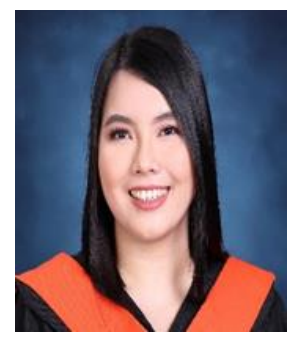

Jobelle P. Panganiban is a graduate of Bachelor of Science in Electronics and Communications Engineering at the Technological University of the Philippines Taguig. Currently, she is working in the engineering division in Analog Devices Inc., General Trias Cavite, Philippines. E-mail: Jobelle.Panganiban@analog.com

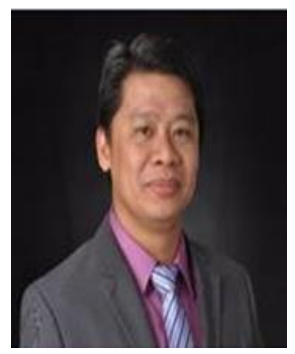

Glenn N. Ortiz is a graduate of Bachelor of Science in Electronics and Communications Engineering at the University of the East in Manila Philippines. He is also a graduate of Master of Technology Management in University of the Philippines Diliman, Quezon City Philippines. His research interests are in industrial automation, manufacturing, and electronics. He is currently the Director of the Industry-based Program of the Technological University of the Philippines Taguig. E-mail: glenn_ortiz@tup.edu.ph

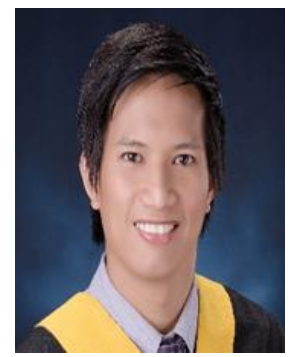

Mark Joseph B. Enojas received a degree of Bachelor of Science in Electronics and Communications Engineering from Technological University of the Philippines Taguig in 2009, Master of Information Technology in University of the Philippines Los Baños, Laguna, Philippines and is currently pursuing Ph.D. in Electrical and Electronics Engineering in University of the Philippines Diliman, Quezon City Philippines. His research interests are on automation, mechatronics, industrial automation, and soft robotics. E-mail: markjoseph_enojas@tup.edu.ph 